\title{
Vias de parto: percepção e preparo de gestantes de uma unidade básica de saúde
}

Delivery routes: perception and preparation of pregnant women at a basic health unit

Vías de parto: percepción y preparación de la gestante en una unidad básica de salud

Ruth Luiza Uchoa de Souza ${ }^{1 *}$, Raquel Ferreira Chaves ${ }^{1}$, Ivana Annely Cortez da Fonseca1.

\section{RESUMO}

Objetivo: Descrever a percepção das gestantes em acompanhamento do pré-natal pelo enfermeiro em uma Unidade Saúde da Família sobre vias de parto. Métodos: Utilizou-se a pesquisa de campo, descritiva, com abordagem qualitativa, à amostragem foi composta por 15 gestantes, a coleta de dados ocorreu na após aprovação no comitê de ética e pesquisa em uma Unidade de Saúde da Família, mediante a aplicação de uma entrevista. Resultados: Foi possível elaborar três grupos temáticos, o primeiro grupo temático trata-se da percepção das gestantes quanto às vias de parto, o segundo refere-se à relação profissional enfermeiro e gestante nas consultas de pré-natal e por fim o terceiro grupo temático abrangerá quais os sentimentos expressados pelas gestantes referentes à decisão sobre a via de parto. Conclusão: Diante da análise do objeto estudado as gestantes não possuíam um conhecimento fundamentado sobre as vias de partos, no conceito técnico/cientifico, além de encontrar o sentimento de medo da dor, tanto relacionado ao parto natural e/ou vaginal quanto no parto.

Palavras-chave: Gestante, Pré-natal, Enfermagem, Parto normal, Parto cesáreo.

\section{ABSTRACT}

Objective: To describe the perception of pregnant women undergoing prenatal care by nurses at a Family Health Unit about delivery routes. Methods: Field research was used, descriptive, with a qualitative approach, the sampling consisted of 15 pregnant women, data collection occurred after approval by the ethics and research committee in a Family Health Unit, through the application of an interview. Results: It was possible to elaborate three thematic groups, the first thematic group deals with the perception of pregnant women regarding the routes of delivery, the second refers to the professional relationship between nurses and pregnant women in prenatal consultations, and finally the third thematic group it will cover the feelings expressed by pregnant women regarding the decision on the mode of delivery. Conclusion: In view of the analysis of the studied object, the pregnant women did not have a grounded knowledge about the routes of childbirth, in the technical/scientific concept, in addition to finding the feeling of fear of pain, both related to natural and/or vaginal delivery and to childbirth.

Keywords: Pregnant woman, Prenatal care, Nursing, Normal delivery, Cesarean delivery.

\section{RESUMEN}

Objetivo: Describir la percepción de las gestantes que reciben atención prenatal por enfermeras de una Unidad de Salud de la Familia sobre las vías de parto. Métodos: Se utilizó investigación de campo, descriptiva, con enfoque cualitativo, el muestreo consistió en 15 mujeres embarazadas, la recolección de datos se produjo luego de la aprobación del comité de ética e investigación en una Unidad de Salud de la

${ }_{1}^{1}$ Faculdade Interamericana de Porto Velho - UNIRON, Porto Velho - RO. *E-mail: ruthluiza28@gmail.com 
Familia, mediante la aplicación de una entrevista. Resultados: Se pudieron elaborar tres grupos temáticos, el primer grupo temático trata sobre la percepción de la gestante respecto a las vías del parto, el segundo se refiere a la relación profesional entre enfermeras y gestantes en las consultas prenatales y finalmente el tercer grupo temático lo cubrirá los sentimientos expresados por las mujeres embarazadas con respecto a la decisión sobre el modo de parto. Conclusión: A la vista del análisis del objeto estudiado, las gestantes no tenían un conocimiento fundamentado sobre las vías del parto, en el concepto técnico-científico, además de encontrar la sensación de miedo al dolor, tanto relacionado con el natural como con el dolor. / o parto vaginal y al parto.

Palabras clave: Embarazada, Prenatal, Enfermería, Parto normal, Parto por cesárea.

\section{INTRODUÇÃO}

Gonçalves MD, et al. (2016), relatam que o pré-natal tem alcançado destaque na atenção básica durante a assistência da gestante e do seu bebê. A consulta de enfermagem que está intrínseca ao pré-natal, é um exercício independente, efetuado de forma privada pelo enfermeiro e tem como propósito garantir condições de promoção a saúde da mãe e da criança levando a melhoria na qualidade de vida de ambos.

O nascimento de um filho traz diversos sentimentos na mulher, o que exige não só da mãe, mas também o reconhecimento e o carinho de todos os que cuidam dela, pois esses sentimentos podem criar conflitos causados pela insegurança, medo e dúvida diante da escolha do parto. Portanto, o pré-natal torna-se um espaço ideal para os profissionais orientarem, aconselharem, observarem e interagirem com as futuras mães para que todas as suas dúvidas possam ser esclarecidas antes do parto (CASTRO GA, et al., 2021).

O enfermeiro deve portar-se sem julgamento e buscando sempre acolher e atender sua gestante de forma humanizada, notando suas emoções, reações e percepções referentes às vias de parto que existem, explanando suas vantagens e desvantagens sobre os tipos de partos (SILVESTRE DR, et al., 2014).

Este estudo propõe contribuir de forma indireta para fomentar a discussão cientifica sobre a temática, colaborando para nortear a tomada de decisão pelos gestores em saúde e para, incentivar o enfermeiro a realizar um pré-natal voltado para motivação e à autonomia que a mulher possui em seu próprio corpo. Buscou-se então como objetivo principal descrever a percepção das gestantes em acompanhamento do pré-natal pelo enfermeiro em uma Unidade Saúde da Família sobre vias de parto.

\section{MÉTODOS}

Este estudo utilizou à pesquisa de campo, descritiva, com abordagem qualitativa, a pesquisa ocorreu em uma Unidade de Saúde da Família, nos dias de Consulta do Pré-Natal com o enfermeiro, foram convidadas a participar 15 gestantes.

A amostra foi de forma não probabilística, proposital ou intencional. Como critérios de inclusão, participou somente as gestantes com idade igual e/ou superior a 18 anos, em pré-natal de baixo risco em qualquer trimestre da gestação, que estavam em pré-natal com o profissional enfermeiro, alfabetizadas ou não, os critérios de exclusão foram as gestantes com transtornos psicológicos e em situação de saúde que impediram a realização da coleta de dados.

Vale ressalta que foram tomadas todas as medidas de precaução contra o Covid-19 para a realização da coleta de dados, a entrevista ocorreu com roteiro semiestruturado, gravado e transcrito por meio de um aplicativo instalado no próprio celular das pesquisadoras "SpeechToText". A coleta de dados iniciou após a aprovação pelo Comitê de Ética e Pesquisa (CEP), Número do parecer 4.659.191, CAAE: 42263420.0.0000.8028 data: 19 de abril de 2021.

Posteriormente a realização das entrevistas, as falas foram e agrupadas em categorias, conforme os temas convergentes. As participantes da pesquisa foram identificadas pelas siglas G1, G2, e assim por diante, no qual o $G$ refere-se a gestante e o numeral a ordem em que forem realizadas as entrevistas, de modo a preservar o anonimato das participantes. 


\section{RESULTADOS E DISCUSSÃO}

Mediante as questões de caracterização, a idade variou entre 18 e 40 anos, com média de 33 anos. Nota-se que o ensino médio predomina entre as participantes da pesquisa e somente duas sinalizaram possuir nível superior. Quanto à raça: cinco gestantes se autodeclararam de cor branca, cinco de cor parda e cinco de cor preta.

Com relação à renda familiar pode se notar que a grande totalidade das gestantes (oito gestantes) se enquadrou na renda entre 1 a 2 salários mínimos, e, quanto à idade gestacional variaram entre 24 semanas a 39 semanas, dos quais 10 multíparas e cinco gestantes primípara, conforme pode ser observado no Quadro 1.

Quadro 1 - Caracterização das participantes.

\begin{tabular}{|c|c|c|c|c|c|c|}
\hline $\begin{array}{c}\text { Código de } \\
\text { Identificação }\end{array}$ & Idade & $\begin{array}{l}\text { Número de } \\
\text { gestação }\end{array}$ & Profissão & $\begin{array}{c}\text { Grau de } \\
\text { Escolaridade }\end{array}$ & $\begin{array}{l}\text { Raça ou } \\
\text { Cor }\end{array}$ & Renda Familiar \\
\hline G1 & 39 & Multípara & Nutricionista & $\begin{array}{c}\text { Ensino } \\
\text { Superior }\end{array}$ & Preta & $\begin{array}{c}3 \text { a } 4 \text { salários } \\
\text { mínimo }\end{array}$ \\
\hline G2 & 40 & Multípara & Vendedora & Ensino Médio & Parda & $\begin{array}{l}3 \text { a } 4 \text { Salários } \\
\text { mínimo }\end{array}$ \\
\hline G3 & 37 & Multípara & $\begin{array}{l}\text { Atendente de } \\
\text { Caixa }\end{array}$ & Ensino Médio & Branca & $\begin{array}{c}1 \text { a } 2 \text { Salários } \\
\text { mínimo }\end{array}$ \\
\hline G4 & 33 & Multípara & Do Lar & Ensino Médio & Preta & $\begin{array}{l}3 \text { a } 4 \text { Salários } \\
\text { mínimo }\end{array}$ \\
\hline G5 & 33 & Multípara & Do Lar & Ensino Médio & Parda & $\begin{array}{l}3 \text { a } 4 \text { Salários } \\
\text { mínimo }\end{array}$ \\
\hline G6 & 33 & Multípara & Cabelereira & Ensino Médio & Branca & $\begin{array}{l}1 \text { a } 2 \text { Salários } \\
\text { mínimo }\end{array}$ \\
\hline G7 & 29 & Multípara & Do Lar & Ensino Médio & Preta & $\begin{array}{l}1 \text { a } 2 \text { Salários } \\
\text { mínimo }\end{array}$ \\
\hline G8 & 24 & Multípara & Frentista & $\begin{array}{l}\text { Ensino } \\
\text { Superior }\end{array}$ & Branca & $\begin{array}{c}1 \text { a } 2 \text { Salários } \\
\text { mínimo }\end{array}$ \\
\hline G9 & 24 & Primípara & Do Lar & Ensino Médio & Preta & $\begin{array}{c}1 \text { a } 2 \text { Salários } \\
\text { mínimo }\end{array}$ \\
\hline G10 & 24 & Multípara & Do Lar & Ensino Médio & Parda & $\begin{array}{c}3 \text { a } 4 \text { Salários } \\
\text { mínimo }\end{array}$ \\
\hline G11 & 22 & Primípara & Tatuadora & Ensino Médio & Parda & $\begin{array}{l}3 \text { a } 4 \text { Salários } \\
\text { mínimo }\end{array}$ \\
\hline G12 & 20 & Primípara & Do Lar & Ensino Médio & Branca & $\begin{array}{c}1 \text { a } 2 \text { Salários } \\
\text { mínimo }\end{array}$ \\
\hline G13 & 18 & Primípara & Estudante & Ensino Médio & Branca & $\begin{array}{l}\text { Não Possui } \\
\text { Renda Fixa }\end{array}$ \\
\hline G14 & 18 & Primípara & Do Lar & Ensino Médio & Parda & $\begin{array}{c}1 \text { a } 2 \text { Salários } \\
\text { mínimo }\end{array}$ \\
\hline G15 & 20 & Multípara & $\begin{array}{l}\text { Agente de } \\
\text { Viagens }\end{array}$ & Ensino Médio & Preta & $\begin{array}{c}3 \text { a } 4 \text { Salários } \\
\text { mínimo }\end{array}$ \\
\hline
\end{tabular}

Fonte: Souza RLU, et al., 2021.

Diante dos resultados adquiridos, foi possível elaborar três grupos temáticos, percepção das gestantes quanto às vias de parto, o segundo refere-se à relação profissional enfermeiro e gestante nas consultas de pré-natal e por fim o terceiro grupo temático abrangerá quais os sentimentos expressados pelas gestantes referentes à decisão sobre a via de parto.

\section{Percepções das gestantes quanto às vias de parto}

Neste grupo temático discutiremos as percepções que as gestantes possuem sobre as vias de parto, sejam naturais e/ou vaginal e cesárea. 
Sobre o parto vaginal e/ou natural, uma única participante G13 menciona ser um processo natural deleitado em um nascimento por via vaginal, e as demais participantes como, por exemplo, a G3 menciona que sua percepção se baseava no que diz respeito à dor durante o partejar e essa dor cessava após o nascimento, a recuperação do pós-parto era rápida, todas as falas estavam baseadas em experiências e conhecimento construído por vivências anteriores e de outras mulheres, é não por explicações respaldadas cientificamente, conforme se observa:

\section{"Entendo que é o parto que ocorre pela via vaginal, basicamente isso" (G13).}

"Eu prefiro o parto normal, porque mesmo que você tenha dor no momento do parto, depois é mais tranquila, quanto ao cesariano, tem as outras complicações na questão do pós-parto" (G3).

Notem que as falas supramencionadas traduzem a percepção que as gestantes têm sobre o parto vaginal e/ou natural, e este entendimento se constrói baseado no conhecimento popular e não em conceito técnico/científico que pode estar entrelaçada ao grau de escolaridade das mesmas.

Em alguns casos, é evidente a existência de uma defasagem educacional entre as mulheres. No entanto, se ocorrer gravidez, a maioria delas tendem a abandonar a escola imediatamente, por motivo de não conseguiram equilibrar as duas situações (MOREIRA AC, et al., 2018).

Corroborando com as falas Velho MB, et al. (2014), descrevem que o parto normal é entendido como um acontecimento natural, de caráter íntimo e privado, e apresenta inúmeros significados culturais e sentimentais. Já Vicente AC, et al. (2017) relatam que o parto normal é aquele que ocorre da forma mais natural possível e sua via de nascimento é a vaginal.

Lançando o olhar para o parto cesariano, as gestantes referem que acreditam que pode machucar 0 bebê e existem complicações durante o parto, sentem medo é um parto que elas não desejam, observa-se nas falas:

"Eu acredito que a mulher sofre mais com o parto cesariano, pois a anestesia pode em algumas vezes machucar a coluna da mulher, e fica muito tempo sem poder fazer seus afazeres e ainda precisa de cuidados de terceiros" (G10).

"É um parto que eu não queria para mim, nem para o meu bebê, acho que pode nos machucar, tenho medo" (G4).

"Sinto que o parto cesariano é mais complicado, já ouvi relatos de amigas, que durante a intervenção cirúrgica aconteceu algumas complicações, penso que é devido a muitos procedimentos invasivos e agressivos, o que eu puder fazer para evitar o cesariano eu vou fazer" (G11).

Diante das falas quando elas foram referenciadas sobre a percepção do parto cesariano suas respostas não se baseavam no conceito técnico/científico, em vez disso, enfatizou-se em suas falas um entendimento voltado para as complicações que este procedimento poderia acarretar, a grande maioria verbalizou que não desejam este tipo de parto além das complicações para seu corpo e mudança da rotina diária dessa mãe.

Corroborando com as falas Travancas LJ e Vargens OM (2020) reafirmam que esse tipo de compreensão quanto à via de parto cesariano ocorre devido ao pensamento emocional da mulher, que cria forma a partir de crenças, ideias existentes ou por experiências traumáticas anteriores. Estes anseios são frequentes nestas gestantes, e que a dor pós-parto, dificuldade de recuperação são riscos que uma cirurgia acarreta e que as dúvidas junto à experiência anterior com a anestesia aumentam a sensação de medo e incerteza (VELHO MB, et al., 2014).

Apesar destes anseios referidos pelas gestantes, houve um registro em que a participante optaria pelo parto cesariano por acreditar que está via seria a ideal para sua situação gestacional. 
"O parto cesariano é o mais recomendado para minha situação e bem-estar do meu bebê" (G14).

O discurso da participante está interligado com a ideia da quanto à indicação da cesariana para o nascimento do bebê. Este parto deve ocorrer sempre visando o bem-estar do bebê, uma opção sempre que o do parto vaginal não for indicado como menciona (BRASIL, 2017).

Retrocedendo textualmente, ao observar o perfil de caracterização à idade gestacional encontra-se entre 24 a 39 semanas, nota se uma incipiência nas práticas de educação em saúde por parte do enfermeiro que acompanha estas gestantes desde o início do pré-natal, como consequência, não era para haver essa realidade de perfil sobre o entendimento das vias de parto, baseado nisso nota-se uma diminuição de concepção de informações básicas transmitidas para as gestantes durante as consultas de pré-natal.

Vale ressaltar a importância do acolhimento prestado dentro do Programa de Humanização no Pré-natal e Nascimento (PHPN) na atuação do enfermeiro na assistência do pré-natal, dando ao profissional a oportunidade de atender as necessidades da gestante. Levando estas mulheres a terem o conhecimento suficiente e atualizado durante a gravidez-puerpério, para assim, desenvolver uma relação produtiva durante toda a gestação (DIAS EG, et al., 2018)

As gestantes necessitam saber o que é um parto vaginal e/ou e cesariano, pois a partir do conceito estabelecido as mesmas conseguirão esclarecer suas dúvidas e anseios referentes aos tipos de parto, e a partir do conceito que elas irão criar uma expectativa referente ao parto que desejam, é nesse momento após o entendimento sobre as vias de parto que a mulher se tornará protagonista das suas escolhas influenciadas pelo entendimento do que é o melhor para ela e seu bebê, e não por influência de terceiros ou conceitos populares.

\section{A Relação Profissional Enfermeiro e Gestante Nas Consultas De Pré-Natal}

Esta temática apresentará as percepções que as gestantes possuem sobre a relação delas com o profissional enfermeiro (a) durante as consultas de pré-natal. Após exaustivas leituras das falas consideramos que a relação é boa e amigável, logo se sentem mais relaxadas, acolhidas e as dúvidas existentes sobre o parto são imediatamente atendidas quando as mesmas perguntam:

"Minha relação com o profissional enfermeiro é maravilhosa, ele me esclarece tudo quando pergunto, quando estou dúvidas eu procuro a informação na internet e trago e pergunto se é verdade, tenho um excelente retorno de informações quanto ao parto e quanto ao crescimento do bebê" (G15).

Diante do exposto Nogueira LDP e Oliveira GS (2017) descrevem que o cuidado qualificado no pré-natal se refere ao processo de uma mulher receber cuidados adequados durante a gravidez, parto, pós-parto. $\mathrm{O}$ profissional envolvido na assistência deve promover seu desempenho profissional em todos os níveis, precisa ser portador de conhecimento e habilidades, para sua prática ser segura e competente para reduzir a baixa adesão ao pré-natal e o mesmo tem competência técnica para sua prática conforme o Decreto no $94.406 / 87$.

Ressaltando um eixo dentro da leitura, observou-se que as gestantes verbalizaram que não gostavam do atendimento, revelando sua insatisfação em relação à consulta de enfermagem, com a enfermeira sabendo que existem dois enfermeiros que realizam o pré-natal (uma mulher é um homem) e dentro da fala ocorreu que quando o pré-natal era realizado com a enfermeira as gestantes não se sentiram acolhidas e quando mudavam as consultas para com o enfermeiro suas visões mudavam completamente quanto à relação desenvolvida enfermeiro/gestante:

"Enfermeira que fez meu primeiro pré-natal, não gostei dela, achei ela muito distante só buscava apenas prescrever exames, [...] decidir consultar com o atual enfermeiro gostei muita da forma que ele me atendeu, e se preocupou comigo e esclareceu minhas dúvidas" (G2). 
"O primeiro enfermeiro que me atendeu foi muito bom, já a segunda é uma enfermeira que deixou um pouco a desejar, como já fiz outros pré-natais tenho uma noção de como funciona [...]" (G14).

Santana FA, et al. (2015) citam essas situações podem ocorrer devido as dificuldades no atendimento, como consulta clínica insuficiente, profissionais despreparados, falhas na graduação relacionada à falta de experiência dos recém-formados, ausência de qualificação profissional, entre outras.

Essa possível falha na assistência pode ocorrer devido um aspecto importante referente às necessidades da organização do fluxo, uma demanda muito grande de atendimento de gestantes e às vezes não tem tempo realizar um exame físico detalhado, ou realizar um procedimento de forma mais correta (LEAL MC, et al., 2018).

É de suma importância que ocorra a receptividade desta gestante durante as consultas de pré-natal, a insatisfação dessas gestantes referentes às consultas pode acarretar um abandono de pré-natal e assim a quebra de uma assistência qualificada e humanizada, para que isso não ocorra o profissional enfermeiro precisa se permitir mergulhar nesta relação enfermeiro/gestante, pois a qualidade desta assistência depende tão somente do acolhimento das suas gestantes e prestação de cuidados contínuos.

\section{Sentimentos expressados pelas gestantes frente à decisão sobre a via de parto}

$\mathrm{Na}$ totalidade das falas das participantes houve a preferência pelo parto normal e/ou natural apesar do sentimento de medo está interligado a esta escolha, porém entendem que o medo faz parte do processo de partejar e que após o nascimento esse medo cessava, e se iniciava um novo sentimento de gratidão, junto com um amor inexplicável, além de preferirem o parto normal e/ou natural, pois o mesmo possibilita uma recuperação mais rápida favorecendo um retorno das atividades diárias, além de entenderem que é o melhor para seu bebê.

Os trechos a seguir exemplificam essa discussão:

"Eu prefiro o parto normal, porque no parto normal mesmo que você tenha dor no momento do parto, depois é mais tranquila a dor é só no momento da passagem bebê, é uma emoção inexplicável, quanto a cesariano, tem as outras complicações na questão do pós-parto" (G3).

"O parto normal é uma emoção muito grande, na hora que nasce já dá para ver a carinha do bebê, e é ainda emocionante quando coloca o bebe nosso peito, a gente sofre um pouco, mas quando a criança sai àquela dor já fica mais aliviada" (G6).

Mediante os trechos o sentimento de sentir-se completa está explicita nas falas, o momento do partejar é algo grandioso que nenhuma dor ou medo que as mesmas sintam, permitem que as participantes deixem de sonhar por esse momento. Este sentimento de se sentir completa está explicita na fala de Velho MB, et al. (2014), trazem que a inserção das mulheres em partos normais, florescem sentimentos maternos, cumplicidade entre mães e bebê, e se sentem como verdadeiramente mãe, sobre a natureza da dor o parto e a capacidade de superação do parto.

As participantes entendem que a decisão pelo tipo de parto compreende um fenômeno que se prorroga por todo processo de gravidez, uma vez que esta decisão cria várias expectativas na gestante, desde o início, e continua sendo referida mesmo depois do desfecho final, persistindo na forma de lembranças e sentimentos assim como (OLIVEIRA VP e PENNA CM, et al., 2018).

Firmando as falas no que diz respeito ao sentimento do medo da dor, de não suporta esse momento, mais que viveriam esse momento por amor ao seu filho está exemplificado abaixo:

"Tenho Nervosismo e medo de não suportar a dor, mais pelo meu filho faço tudo" (G2). 
Reis CC, et al. (2017) descrevem que geralmente as gestantes referem se ao parto vaginal enfatizando medo, dor e insegurança, uma condição de dependência, porém esses sentimentos não privam as mesmas de se sentirem em um momento maravilhoso durante o partejar.

Nota-se que o medo que as participantes expressam sobre o parto vaginal está relacionado ao medo da dor, de não suportar o partejar, porém não é o que está evidenciado quando referidas os sentimentos expressados sobre o cesariano, o medo está totalmente vinculado a malefícios que este procedimento pode acarretar para a saúde mãe e bebê, além de referirem muito à questão do pós-parto.

"Medo de acontecer algo comigo e com o meu bebê" (G3).

"Acho que traz dificuldades depois no pós-parto, devido ao processo de reabilitação, por ser mais longo e a anestesia” (G4).

Ferreira AF (2020) traz em seu estudo que a insatisfação dificuldade no pós-parto e desagrado pelo parto cesariano se deve principalmente ao efeito da anestesia geral, que impede o contato com o bebê. Isso descreve sentimentos de ansiedade e medo, da mesma forma como as participantes mencionam em suas falas. Hoje em dia, as gestantes estão preocupadas de o parto cesariano ser algo doloroso. Essa dor é considerada forte, dolorosa, exaustiva e terrível. Relacionado ao medo de acontecer algo com o bebê, levando as mesmas a ter pavor do parto cesariano (PEREIRA RR, et al., 2011).

Dentro da fala das participantes pode-se perceber que o medo de acontecer algo com o bebê é o anseio mais recorrente encontrada dentro dos discursos, quando referenciadas ao que sentem sobre o parto cesariano, o não conhecimento dos benefícios do parto cesariano acarreta a exacerbação do medo, pois se recebessem informações a respeitos dos tipos de parto que existem e quais indicações são especificas para cada via de parto, traria mais tranquilidade e menos insegurança para as mães.

Dentro dos achados deste estudo referenciou aquelas que possuem um sentimento positivo para o parto cesariano, pois elas sentiam-se bem, pois sabiam que aquela via seria a ideal para o bem está de ambos e aquelas que aceitaram a cesariana porque realizariam a laqueadura. Os trechos abaixo trazem as falas para exemplificar melhor a justificativa acima:

"É um parto mais complicado porque é um risco muito grande, isso me trás muito medo porque toda cirúrgia tem um risco, mas às vezes é a melhor opção, foi o que aconteceu comigo e com minha filha e sei que tudo vai dar certo" (G14).

"Para mim, eu gostaria de ter parto normal, mas o meu fico feliz de fazer o Cesariano porque eu vou conseguir realizar a laqueadura" (G4).

Apesar de inúmeros estudos comprovarem o aumento das cesarianas no Brasil conforme Loureiro RC, et al. (2021) globalmente, o Brasil ocupa o segundo lugar em cesariana (56\%). Porém a realidade da população estudada é bem diferente, pois elas lutam para não seguirem o caminho do parto cesariano, a preferência pelo parto cesariano ocorre em um pequeno número de casos e está relacionada aos seguintes fatores: o desejo pela laqueadura após cirurgia e a tocofobia (PIMENTEL TA e FILHO EC, 2016).

O enfermeiro é peça fundamental para este tipo de assistência, o profissional precisa ser qualificado para se envolver em estratégias de promoção da saúde, prevenção de doenças, e um atendimento humanizado. Para tal, o enfermeiro desenvolve um plano de cuidados nas consultas de pré-natal, com base nas necessidades identificadas e priorizadas, estabelece Intervenção, orientação e referência para outros serviços, além de promover a interdisciplinaridade (GOMES CB, et al. 2019).

Porém dentro das falas os sentimentos de medo são o que direcionam as mesmas em optar por uma via de parto para o nascimento, escolher e decidir sobre a forma de partejar precisam ser direcionados através de conhecimentos fidedignos, acompanhamento da gestação de forma assídua e humanizada.

Dessa forma, a preparação das mulheres grávidas para o parto inclui a adoção de uma série de medidas do enfermeiro que a assiste, levando a prática de atividades destinadas a proporcionar às mulheres a possibilidade de vivenciar a experiência do parto gerando na mente das mesmas que é um processo 
fisiológico, para que as mesmas se sintam protagonista. Preparação da mulher sem medo e tensão, proporcionando um conforto físico e mental para a parturiente se sentir livre de traumas e medos, é uma das funções da equipe de saúde e o profissional enfermeiro deve atuar de forma humanizada para promover a participação efetiva da gestante na decisão do parto é, ou seja, a figura central do processo, direitos e sua autonomia preservada (MIRANDA DB, et al. 2014).

\section{CONCLUSÂO}

Diante da análise do objeto estudado as gestantes não possuíam um conhecimento fundamentado sobre as vias de partos, no conceito técnico/cientifico, além de encontrar nas falas o sentimento de medo da dor, tanto relacionado ao parto natural e/ou vaginal e o parto cesariano, para sanar esta problemática, vale relembrar a importância da educação permanente e capacitação periódica do profissional enfermeiro que realiza o pré-natal, tal responsabilidade é compartilhado com gestor da unidade frente a equipe de saúde. A visibilidade deste tema é essencial para a o aumento da produção e discussão cientifica assim como nortear a tomada de decisão do enfermeiro, gestor em realizar um Pré-natal voltado para motivação e à autonomia da mulher na sociedade, frente a escolha sobre a via de parto.

\section{REFERÊNCIAS}

1. BRASIL. Ministério da Saúde. Secretaria de Ciência, Tecnologia e Insumos Estratégicos. Departamento de Gestão e Incorporação de Tecnologias em Saúde. Diretrizes nacionais de assistência ao parto normal. 2017; 51.

2. CASTRO GA, et al. Acadêmicas de enfermagem frente as práticas educativas com gestantes: relato de experiência. Revista Eletrônica Acervo Saúde, 2021; 4: e7061.

3. DIAS EG, et al. Ações do enfermeiro no pré-natal e a importância atribuída pelas gestantes. Revista Sustinere, 2018; 6:52-62.

4. FERREIRA AF. Parto sem medo: projeto para a prevenção da depressão pós-parto. Dissertação de mestrado Enfermagem de Saúde Materna e Obstetrícia, 2020. p. 124.

5. GONÇALVES MD, et al. Atenção ao pré-natal de baixo risco: atitudes dos enfermeiros da estratégia saúde da família Revista Enfermagem, 2016 24: 6.

6. GOMES CB, et al. Consulta De Enfermagem No Pré-Natal: Narratives De Gestantes E Enfermeiras. Texto contexto - enferm, 2019; 28.

7. LOUREIRO RC, et al. Cesariana de gestante com placenta prévia e acretismo seguido de histerectomia devido sangramento maciço. Revista Eletrônica Acervo Saúde, 2021; 13: e5787.

8. LEAL MC, et al. Saúde reprodutiva, materna, neonatal e infantil nos 30 anos do Sistema Único de Saúde. Ciência \& Saúde Coletiva. 2018; 23: 6.

9. MIRANDA DB, et al. Do imaginário ao real: mitos e medos acerca do parto normal. Tempus, actas de saúde colet, 2014; 95-108.

10. MOREIRA AC, et al. Características clínicas e epidemiológicas dos partos ocorridos em um hospital maternidade. Revista de Medicina. 2018; 97(6): 554-560.

11. NOGUEIRA LDP, OLIVEIRA GS. Assistência Pré-Natal Qualificada: As Atribuições Do Enfermeiro - Um Levantamento Bibliográfico. Revista de Enfermagem e Atenção Saúde, 2017.

12. OLIVEIRA VP, PENNA CM. Cada parto é uma história: processo de escolha da via de parto. Rev. Bras. Enferm, $2018 ; 71$.

13. PEREIRA RR, et al. A dor e o protagonismo da mulher na parturição. Revista Brasileira de Anestesia. 2011. e382388

14. REIS CC, et al. Percepção Das Mulheres Sobre A Experiência Do Primeiro Parto: Implicações Para O Cuidado De Enfermagem. Cienc. enferm. 2017. 23:2.

15. SANTANA FA, et al. Fatores que influenciam a gestante na escolha do tipo de parto. Revista da Faculdade de Ciências Médicas. 2015; 17: 3.

16. SILVESTRE DR, et al. Via De Parto Orientada No Pré-Natal E A Escolha Da Enfermeira No Seu Próprio Parto. Journal of Nursing. 2014; 8: 12.

17. PIMENTEL TA, FILHO EC. Fatores que influenciam na escolha da via de parto cirúrgica: uma revisão bibliográfica. Centro Universitário de Brasilia. 2016; e187-199

18. TRAVANCAS LV, VARGENS OM. Fatores Geradores Do Medo Do Parto: Revisão Integrativa. Revista de Enfermagem. 2020; 10: 1-24.

19. VELHO MB, et al. Parto Normal E Cesárea: Representações Sociais De Mulheres Que Os Vivenciaram. Rev. Bras. Enferm, 2014; 67: 2.

20. VICENTE AC, et al. Parto Cesário E Parto Normal: Uma Abordagem Acerca De Riscos E Benefícios. Temas em Saúde, 2017; 17: 4. 